\title{
Regulatory Process
}

National Cancer Institute

\section{Source}

National Cancer Institute. Regulatory Process. NCI Thesaurus. Code C48805.

A process that acts to control the rate or manner in which another process progresses

or a product is formed. 